\title{
Johnsongrass (Sorghum halepense) Seed Dispersal in Corn Crops under Mediterranean Conditions
}

\author{
Judit Barroso, Dionisio Andújar, Carolina San Martín, César Fernández-Quintanilla, and José Dorado*
}

\begin{abstract}
Natural dissemination of johnsongrass seeds as well as the effect of combine harvesting on this process were studied in corn fields. The estimation of natural dispersal was carried out by two different methods, collecting seeds throughout the season using seed traps and sampling soil-surface seed abundance before harvest using a vacuum device. Both methods showed the same dispersal pattern. A minimum of $84.6 \%$ was dispersed in the first $2 \mathrm{~m}$ from the focus and a maximum of $1.6 \%$ was dispersed beyond the first $5 \mathrm{~m}$. An average of $76.3 \%$ of these dispersed seeds were lost or buried after shedding but before harvest. Seed dispersal by the combine harvester was estimated from the difference between soil-surface seed abundance in the same sites pre and postharvest. Although the quantity of seeds dispersed by the combine was similar to those dispersed by natural factors, dispersal distances were significantly higher. Around $90 \%$ of the dispersed seeds were found in the first $5 \mathrm{~m}$ forward and backward of the combine direction from the infestation source, and $1.6 \%$ of the seeds were found beyond $22 \mathrm{~m}$ forward and $10 \mathrm{~m}$ backward of the combine direction from the infestation source. A large proportion of the seeds dispersed were dormant or not viable. It is concluded that the major role of sexual reproduction in johnsongrass population dynamics may be to spread the risks, promoting dispersal in time and space.
\end{abstract}

Nomenclature: Johnsongrass, Sorghum halepense (L.) Pers. SORHA; corn, Zea mays L.

Key words: Natural seed dispersal, combine harvester dispersal, grain maize, dispersal pattern.

Johnsongrass is a perennial weed causing severe problems in many crops in the world (Holm 1977). This weed may interfere with crops by direct competition for sunlight, moisture, and mineral nutrients, or by allelopathic influences on the crop (Lolas and Coble 1982). In maize crops, dense johnsongrass infestations may entirely prevent grain production (Bendixen 1986). A density of three rhizomes johnsongrass plants in $9.8 \mathrm{~m}$ of row was considered critical to avoid yield losses above $5 \%$ of full-season weed-free maize (Ghosheh et al. 1996).

Although sexual and vegetative reproduction occurs simultaneously, vegetative reproduction by rhizomes has generally received more attention. A single johnsongrass plant can produce up to 28,000 seeds and 40 to $90 \mathrm{~m}$ of rhizomes per growing season (Horowitz 1973). Apparently, seeds are the principal means of introduction of johnsongrass into a new area, whereas rhizomes are the primary means of dispersal in the field (Mitskas et al. 2003). Only a reduced proportion of the seeds shed are able to produce seedlings. Ghersa et al. (1993) estimated that the ratio of recruited seedlings to seeds shed was only $1 \%$ under the parent plant but increased progressively as they moved from that focal area. In this experiment, soil tillage was strictly required for seedling recruitment.

Horowitz (1973) found that $80 \%$ of the rhizomes produced by a johnsongrass plant were present within $1 \mathrm{~m}$ radius from the plant center, with approximately circular shape and no preferential direction of expansion. However, studies conducted in maize fields in Spain showed that johnsongrass patches presented in the interior of the field were 1.81 times longer in the direction of tillage (Andújar et al. 2011). Two possibilities were hypothesized for this anisotropic fact: the spread of rhizomes by the different tillage

\footnotetext{
DOI: 10.1614 /WS-D-11-00099.1

* First author: Fulbright Post Doctorate Research Associate, Department of Land Resources and Environmental Sciences, Leon Johnson Hall, Montana State University, Bozeman, MT 59717-3120; second, third, fourth, and fifth authors: Post Doctorate Research, Graduate Student, Research Professor, and Research Scientist, Department of Plant Protection, Instituto de Ciencias Agrarias, CSIC, Serrano 115 B, 28006 Madrid, Spain. Corresponding author's E-mail: judit.barroso@montana.edu
}

operations, and the seed dispersal by combine harvesters. Although johnsongrass seed dispersal has already been studied in Argentina (Ghersa et al. 1993; Scopel et al. 1988), environmental and cropping conditions present in Spain are much different.

Several studies have focused on the effects of different agricultural practices in seed dispersal (Barroso et al. 2006; Heijting et al. 2009; Howard et al. 1991; Rew and Cussans 1997; Shirtliffe and Entz 2005). All of them agree that combine harvesting has the potential to disperse seeds great distances. Rew et al. (1996) found that harvesting may disperse seeds of poverty brome (Bromus sterilis L.) more than $50 \mathrm{~m}$. The relative importance of combine dispersal on the overall spread of a weed depends mainly on the number of seeds present in the plant at harvest time. In the case of wild oat (Avena fatua L.) in winter wheat crops in the U.K., less than $10 \%$ remained on the plants at harvest (Barroso et al. 2006). This value ranged from 4 to $20 \%$ in the case of sterile oat (A. sterilis L.) in winter barley in Spain. In the latter case, tillage operations moved more seeds (but lower distances) than combine operations. Heijting et al. (2009), working with silage maize, found that species that had the seeds on the plant at the time of harvest were spread further in the traffic direction than species whose seeds had been placed on soil surface. The use of a cultivator after harvesting significantly increased seed dispersal. In the specific case of johnsongrass in grain maize crops, the combine harvester dispersed a small proportion of the seeds produced (only $20 \%$ were still on the panicles at harvest) but it dramatically increased the distance of seed dispersal (Ghersa et al. 1993).

The patchy distribution of $S$. halepense within arable fields provides the potential to reduce herbicide use by only treating the infested areas (Andújar et al. 2011). However, the economic feasibility of using site-specific weed management (SSWM) will be conditioned, among other factors, by the frequency of re-mapping (Barroso et al. 2004; Van Wychen et al. 2002). If the rate and pattern of spread of this weed species could be predicted, a weed map from $1 \mathrm{yr}$ could be used for following application in the next years, which would be desirable in terms of the feasibility of SSWM. 
Table 1. Maize crop characteristic and field operations during the years 2007, 2009, and 2010.

\begin{tabular}{|c|c|c|c|c|c|c|}
\hline \multirow[b]{2}{*}{ Season } & \multicolumn{2}{|c|}{ Tillage } & \multirow{2}{*}{$\frac{\text { Sowing }}{\text { Date }}$} & \multicolumn{2}{|c|}{ Fertilizer } & \multirow{2}{*}{$\frac{\text { Harvest }}{\text { Date }}$} \\
\hline & Type & Date & & Type & Date & \\
\hline \multirow[t]{5}{*}{2007} & Disc harrow & October 29, 2006 & \multirow[t]{5}{*}{ April 3, 2007} & $400 \mathrm{~kg} 8-15-15$ & March 28, 2007 & \multirow[t]{5}{*}{ November 14, 2007} \\
\hline & Moldboard & November 27, 2006 & & 300 kg Urea (46\%) & June 4, 2007 & \\
\hline & Disc harrow & March 29, 2007 & & & & \\
\hline & Cultivator with roller & March 30, 2007 & & & & \\
\hline & Ridging plow & June 4, 2007 & & & & \\
\hline \multirow[t]{4}{*}{2009} & Disc harrow & October 29, 2008 & \multirow[t]{4}{*}{ April 13, 2009} & $500 \mathrm{~kg} 8-15-15$ & March 28, 2009 & \multirow[t]{4}{*}{ October 28, 2009} \\
\hline & Moldboard & December 12, 2008 & & 240 kg Urea (46\%) & June 8, 2009 & \\
\hline & Disc harrow & March 6, 2009 & & & & \\
\hline & Cultivator with roller & March 27, 2009 & & & & \\
\hline \multirow[t]{4}{*}{2010} & Disc harrow & November 29, 2009 & \multirow[t]{4}{*}{ April 7, 2010} & $5008-15-15$ & March 25, 2010 & \multirow[t]{4}{*}{ October 28, 2010} \\
\hline & Moldboard & December 18, 2009 & & 240 kg Urea (46\%) & June 9, 2010 & \\
\hline & Disc harrow & March 11, 2010 & & & & \\
\hline & Cultivator with roller & March 29, 2010 & & & & \\
\hline
\end{tabular}

The objective of this work was to contribute to the existing knowledge on the dispersal of johnsongrass, investigating the pattern of seed shedding and natural dissemination under Mediterranean-type conditions and the effect of combine harvesting on seed dispersal.

\section{Materials and Methods}

Study Site. Experiments were conducted during 2007, 2009, and 2010 at La Poveda Research Farm, $25 \mathrm{~km}$ East from Madrid (Central Spain, $40^{\circ} 18^{\prime} \mathrm{N}, 3^{\circ} 29^{\prime} \mathrm{W}, 618$-m elevation). The experimental field ( 4 ha in size) was located on a flat alluvial plain in the Jarama River basin. The soil has a sandyloam texture with $39 \%$ sand, $47 \%$ silt, and $14 \%$ clay. Grain maize (cv. Helen, FAO 700 class hybrid) was sprinkler irrigated and grown with $0.75-\mathrm{m}$ row spacing and a population of 80,000 plants ha ${ }^{-1}$. All agronomic operations (tillage, sowing, fertilization, and harvesting) were conducted in the NNE-SSW direction (Table 1). Six johnsongrass patches with different sizes and densities were artificially created in 2007 by planting different densities of rhizomes. Although these patches were originally created to study longterm patch dynamics, they provided adequate conditions to study seed dispersal. Patches P1, P2, and P3 measured $100 \mathrm{~m}^{2}$ $(10 \mathrm{~m}$ by $10 \mathrm{~m})$ and had an initial density of approximately 10 plants $\mathrm{m}^{-2}$. Patches $\mathrm{P} 4, \mathrm{P} 5$, and $\mathrm{P} 6$ measured $10 \mathrm{~m}^{2}$ $(3.3 \mathrm{~m}$ by $3.3 \mathrm{~m})$. Initial density of $\mathrm{P} 4$ and $\mathrm{P} 5$ was, approximately, 10 plants $\mathrm{m}^{-2}$, whereas the density of $\mathrm{P} 6$ was 4 plants $\mathrm{m}^{-2}$. In 2010, an additional patch (P7) was included in the study. This patch was originated from seven johnsongrass buds sown in 2007 in a single line, with buds separated $8 \mathrm{~m}$ each. All the patches were situated relatively near the field border (approximately $30 \mathrm{~m}$ ) to facilitate access. Irrigation was conducted weekly from mid June to late August, with a total of 600 to $650 \mathrm{~L} \mathrm{~m}^{-2}$. Other crop and field operation characteristics are shown in Table 1. The wind direction and speed were registered hourly in a weather station located a few meters away from the studied field.

Natural Seed Dispersal. Natural seed dispersal was studied in 2009 and 2010 in P4, P5, and P6 patches. These patches were kept during both growing seasons in their original size $\left(10 \mathrm{~m}^{2}\right)$ by weeding all the johnsongrass plants emerged outside the established edges.

Seed shedding was monitored using two procedures: seed traps and vacuum sampling. Seed traps consisted in plastic pots of $17 \mathrm{~cm}$ of diameter fixed to a wood stick of $50-\mathrm{cm}$ height that was stuck in the soil. Pots stayed 30 to $35 \mathrm{~cm}$ above the soil surface in order to avoid seed predation. A second pot of the same size was placed inside the fixed pot in order to facilitate emptying the pots for sampling. The bottom of the inside pot was covered with a plastic mosquito net to avoid seed losses and allowing water to pass through the mesh. The traps were located in the four directions (NNE, SSW, ESE, and WNW) at six distances of the patch edges: $0.50,1.25,2.00,2.75,3.50$, and $5.00 \mathrm{~m}$. Traps were placed at $0.75-\mathrm{m}$ intervals (in the middle of each inter-row) with the exception of the last whose interval was $1.5 \mathrm{~m}$ (Figure 1a). Seeds in the traps were collected fortnightly since middle July up to harvest. Collected seeds were taken to the lab where they were counted and classified into full seeds (containing normal caryopses) and empty, broken, or shriveled seeds. This classification was made visually by pressing the seeds slightly with a forceps. Seeds apparently in good condition were stored for further germination tests.

In order to sample soil-surface seed abundance before harvest, we used the vacuum device system proposed by Evans et al. (2009). A hand-held blower-vacuum (Stihl ${ }^{\mathrm{TM}}$ model SH 86, STIHL Incorporated, 536 Viking Drive, Virginia Beach, VA 23452) equipped with a black plastic tube $(11.4 \mathrm{~cm}$ inside diameter, $80 \mathrm{~cm}$ length) was used to vacuum an area of $452.4 \mathrm{~cm}^{2}$ delimited by a circular frame $24 \mathrm{~cm}$ in diameter. The circular frame had a wall of $25 \mathrm{~cm}$ in height, so that it was partially buried in the soil to prevent the vacuum from collecting seeds outside the sampling area. A nylon stocking (15-cm length) was placed at the end of the device to collect the seeds. The day previous to maize harvest, all the patches were sampled in two directions: perpendicular to the crop rows (ESE-WNW) and in the same direction that crop rows (NNE-SSW). Sampling in the perpendicular direction was conducted at nine distances from the patch edge: $0.50,1.25$, $2.00,2.75,3.50,5.00,6.50,8.00$, and $11.00 \mathrm{~m}$. Sampling in the row direction was conducted at 16 distances: $0.50,1.25$, $2.00,2.75,3.50,5.00,6.50,8.00,11.00,14.00,20.00$, 26.00, 32.00, 38.00, 44.00, and $50.00 \mathrm{~m}$ (Figure 1b). Three samples were obtained at each distance. In the case of perpendicular sampling, the three samples were in the same row with a $1-\mathrm{m}$ distance between them. In the case of parallel sampling, samples were taken in three consecutive rows.

Seed Dispersal by Combine Harvester. Combine dispersal was studied in the patches P4, P5, and P6 in 2009 and in the 
a)
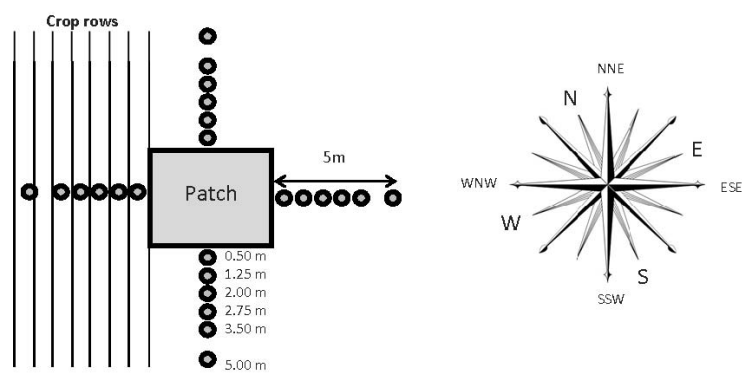

b)

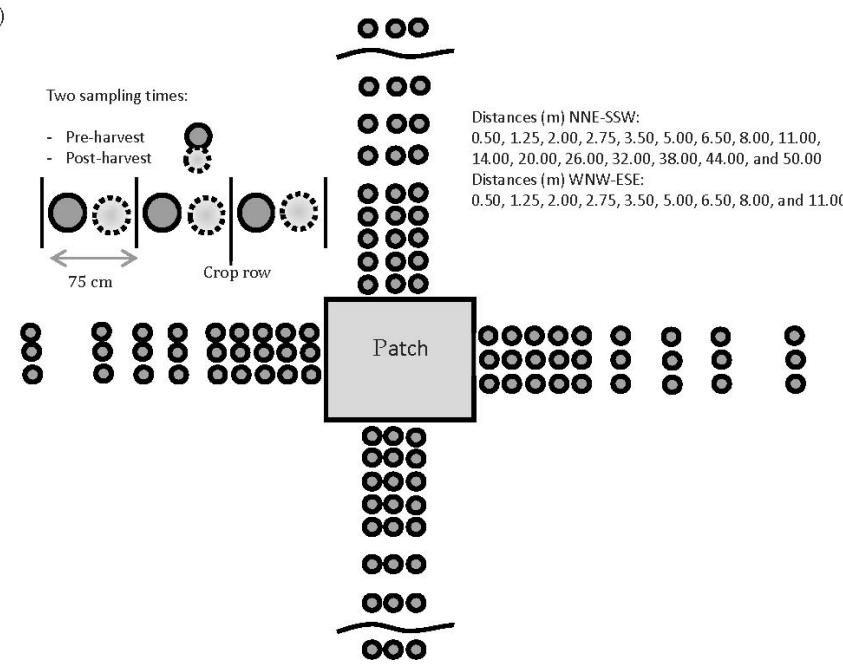

Figure 1. Sampling scheme in the studies conducted to determine (a) natural dispersal using seed traps and (b) natural and combine dispersal using a vacuum device.

patches P1, P4, P5, P6, and P7 in 2010. In 2010, patches P4, $\mathrm{P} 5$, and P6 were studied in the four directions, whereas P7 and P1 were studied only in one direction: in P7 in the forward direction and in P1 in the backward direction. The day after harvesting, the same vacuum sampling procedure described above was conducted. Seed dispersal associated with combine harvesting was estimated by subtracting seed collected preharvest from those collected postharvest. Postharvest sampling was always conducted in a site besides preharvest sampling (Figure 1b). The combine (Claas lexion 480, CLAAS Ibérica SA, Zeus 5, 28880 Meco, Madrid, Spain) had a swath width of $4.5 \mathrm{~m}$, harvesting six maize rows. Working speed was $4.5 \mathrm{~km} \mathrm{~h}^{-1}$.

Seed Shedding Pattern and Germination Tests. A parallel experiment was carried out in the patches P1, P2, and P3 during the $3 \mathrm{yr}$ to characterize the seed shedding pattern. At the end of June, 14 seed traps (equal to those used for studying natural seed dispersal described above) were located inside the patches in 14 consecutive rows, at $1 \mathrm{~m}$ from the edge of the patch in the SSW direction. Sampling was conducted weekly in 2007 and 2009 and fortnightly in 2010, with the last sampling day coinciding with the day of harvest. The collected seeds were taken to the lab to be counted. In 2009 and 2010, seeds were also classified according with their visual and tactile state; seeds in good apparent condition were stored for germination tests. In the $3 \mathrm{yr}$, johnsongrass density (plants $\mathrm{m}^{-2}$ ) in all the patches was measured in May by walking through the inter row area and sampling a 0.66 by $0.33 \mathrm{~m}$ quadrat each $2 \mathrm{~m}$.

Germination tests were conducted in 2010 with mature seeds harvested in 2009 (then stored in lab for almost $1 \mathrm{yr}$ ) and in 2010 (collected some weeks in advance). Seed germination (i.e., visual appearance of the radicle of at least $1 \mathrm{~mm}$ ) was recorded on three replications of 50 seeds placed on a double layer of filter paper in a 9-cm Petri dish moistened with $3.5 \mathrm{ml}$ of sterilized water, in the two collections for each date. Tests were conducted in a growth chamber under controlled conditions (12/12 h light/dark photoperiod and $30 \pm 1 / 20 \pm 1 \mathrm{C}$ thermoperiod) (Ghersa et al. 1993). Petri dishes were sealed with parafilm to maintain humidity during $15 \mathrm{~d}$. At the end of this period germinated seeds were counted. No further tests were conducted to establish if nongerminated seeds were dormant or nonviable.

Data Analysis. Statistical analyses were performed using the Statistical Product and Service Solutions (SPSS) software (SPSS 2010). Seed dispersal data were analyzed by a general linear model (GLM) to study how the different factors (year, patch, direction, and distance) affected to the numbers of seeds collected. The dispersion pattern was analyzed by fitting a nonlinear regression to the percentage of collected seeds according to the equation:

$$
Y=a \mathrm{e}^{-b X}
$$

where $Y$ is the percentage of seeds shed at each distance, $a$ is a parameter indicating the proportion of shed seed at $0 \mathrm{~m}$ from the infestation source (\%), $b$ is a parameter that indicates how fast the shed seeds decrease with distance and $X$ is the different distances from the patch edge $(\mathrm{m})$.

A regression analysis was conducted between the collected seeds and the plant density (in May) to establish the relationship between both variables.

\section{Results and Discussion}

Natural Seed Dispersal. Apparently, natural dispersal of johnsongrass is favored by three major traits of this species: (1) tall size, (2) flexible panicles, and (3) small seeds. Indeed, johnsongrass panicles are generally produced above the maize canopy, with most seeds being released at heights close to $2 \mathrm{~m}$. In addition, the slender panicles of this species are generally bent in the wind direction, enhancing seed dispersal in that direction. The relatively small mass $(2.6 \pm 0.5 \mathrm{mg})$ of johnsongrass seeds is another factor that should contribute to wind dispersal. Because of all these factors, we hypothesized that natural seed dispersal played an important role in population spread. According with our results, $98 \%$ of johnsongrass seeds were shed inside a radius of $5 \mathrm{~m}$. This dispersal distance is larger than those reported for wild chervil [Anthriscus sylvestris (L) Hoffmann], wild oat, and poverty brome (Barroso et al. 2006; Rew et al. 1996).

In relation to natural seed dispersal, a directional effect was observed with similar trend in both years, although only significant differences were found in 2010 (Figure 2). This year, the number of seeds collected in the ESE (7,694 seeds $\left.\mathrm{m}^{-2}\right)$ and NNE $\left(6,293\right.$ seeds $\left.\mathrm{m}^{-2}\right)$ directions were significantly higher than in the directions WNW $(3,465$ seeds $\left.\mathrm{m}^{-2}\right)$ and SSW $\left(2,370\right.$ seeds $\left.\mathrm{m}^{-2}\right)$. Consequently, the highest dispersal distances were observed in the ESE and NNE 
a)

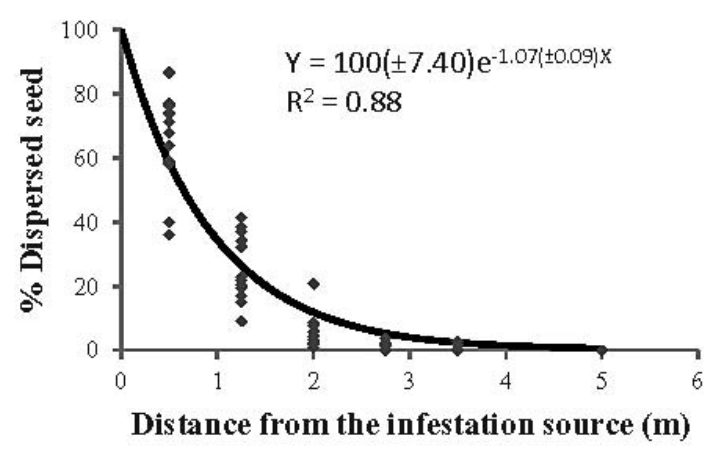

c)

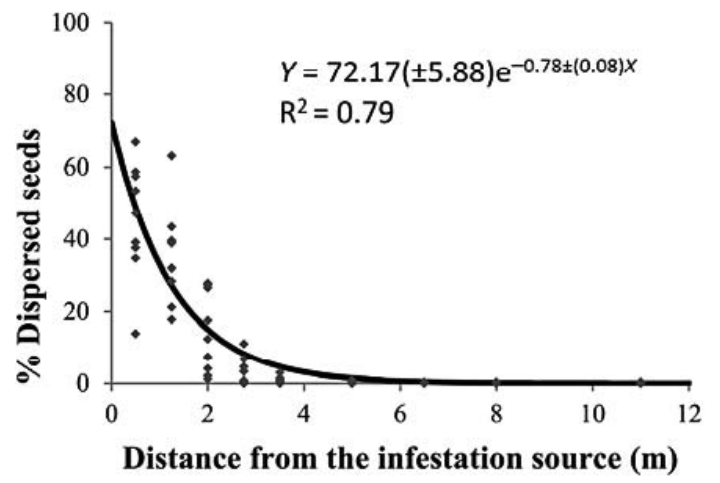

b)

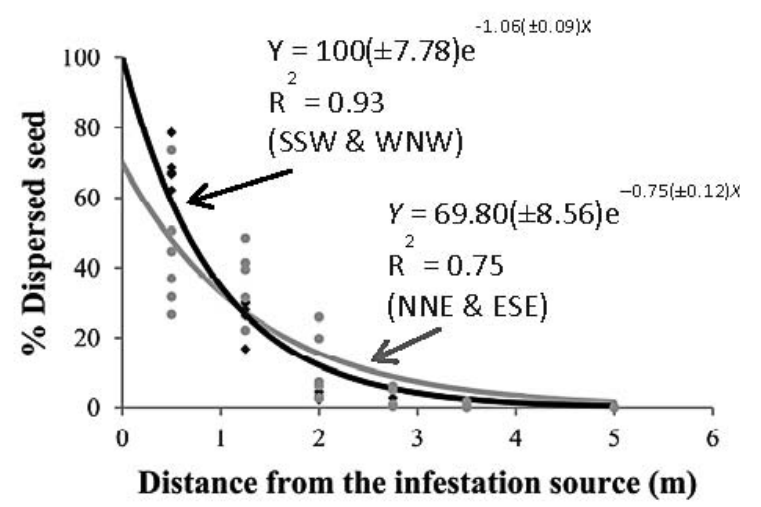

d)

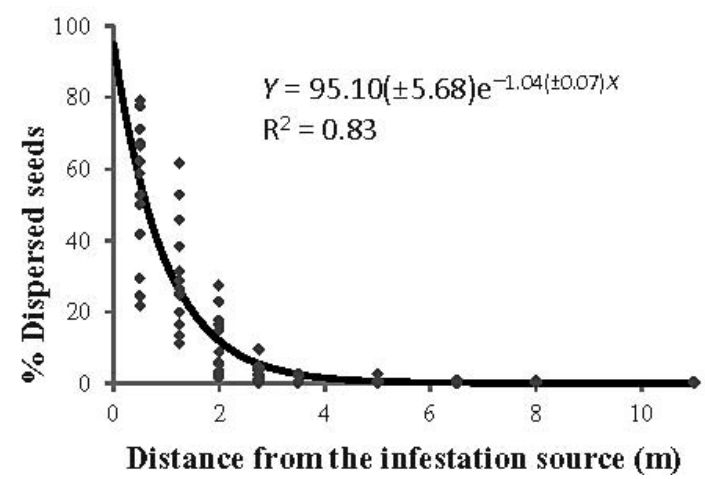

Figure 2. Natural dispersal of the johnsongrass seeds in a corn field: (a) 2009, seed trap method, all directions; (b) 2010, seed trap method for both SSW and WNW and NNE and ESE directions; (c) 2009, vacuum sampling, all directions; and (d) 2010, vacuum sampling, all directions.

directions, with $85 \%$ of the seeds collected in the first $2 \mathrm{~m}$ and up to $1.6 \%$ of seeds found beyond the first $5 \mathrm{~m}$. In 2009, the magnitude of seed shedding was not significantly different in the four directions, but similar to 2010 more seeds were collected in the directions ESE $\left(2,825\right.$ seeds $\left.\mathrm{m}^{-2}\right)$ and NNE $\left(2,848\right.$ seeds $\left.\mathrm{m}^{-2}\right)$ than in WNW $\left(1,332\right.$ seeds $\left.\mathrm{m}^{-2}\right)$ and SSW $\left(1,329\right.$ seeds $\left.\mathrm{m}^{-2}\right)$. Eighty-eight percent of the collected seeds were obtained in the first $2 \mathrm{~m}$ from the patch edge and only $0.5 \%$ of the seeds were dispersed beyond $5 \mathrm{~m}$ from the edge. Since the directional pattern of winds was similar in both years (Figure 3), the differences in the natural seed dispersal data with the experimental year could be explained by the different magnitude of seed collected in traps, which was significantly higher in $2010\left(4,985\right.$ seeds $\left.\mathrm{m}^{-2}\right)$ than in 2009
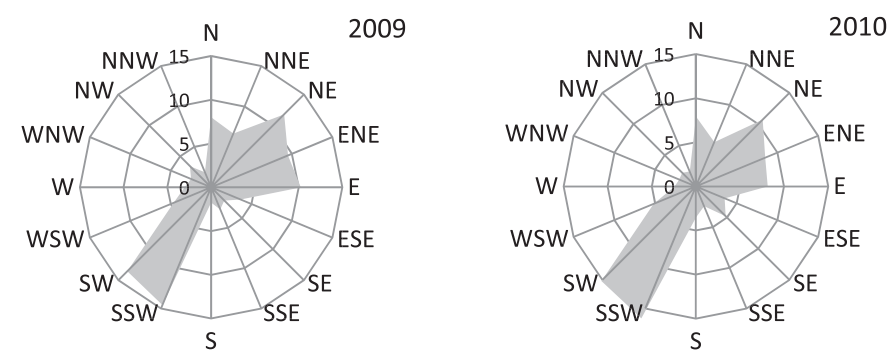

Figure 3. Compass rose for the registered high winds $\left(>10 \mathrm{~km} \mathrm{~h}^{-1}\right)$ in the farm's weather station during the seed shedding period of 2009 and 2010.
(2,083 seeds $\left.\mathrm{m}^{-2}\right)(\mathrm{P}<0.001$, data from GLM not shown). The observed differences between directions are likely to be associated with prevailing winds. In both years, the predominant winds in the study area were coming from SW-SSW as well as from NE. Considering only the winds over $10 \mathrm{~km} \mathrm{~h}^{-1}$, it can be observed that the strongest winds came from SW or SSW (Figure 3). This would explain the larger number of seeds collected in the NNE traps. Winds in the NW-SE direction were very scarce due to the proximity of a high cliff that prevents winds circulating in such direction. Nevertheless, the wind by itself cannot explain the high number of seeds collected in the ESE direction. We observed that johnsongrass plants in the patches were lightly (in 2009) and severely (in 2010) bent toward the ENE direction. This bending, together with the wind effect, resulted in twice as much seeds shed in NNE and ESE directions than in the opposite directions. Considering that strong winds $\left(>15 \mathrm{~km} \mathrm{~h}^{-1}\right.$ ) were only occasional (frequency 0.039 ) in the study area, the dispersal magnitudes can be considerably higher in windy areas.

The numbers of seeds vacuumed from the soil surface at harvest time were much lower than the values obtained with the seed traps. On the average, only $24 \%$ of the seeds shed during the growing season were vacuumed at harvest. In 2009, vacuumed seeds represented $41 \%$ of the total seeds collected in traps and in 2010 this percentage decreased up to $6.5 \%$. Evans et al. (2009) found that sampling efficiency of the 


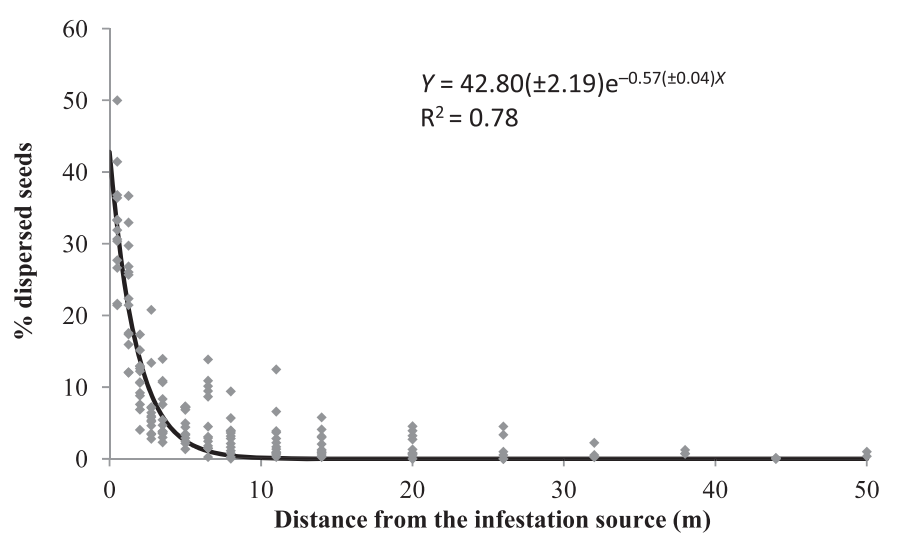

Figure 4. Natural and combine dispersal of johnsongrass seeds (2009 and 2010 data).

vacuum generally declined over time. In only one week, they observed for a cereal field habitat that the sampling efficiency to vacuum medium sized seeds (similar to johnsongrass seed size) decreased from 98 to $75 \%$. This decrement was mostly due to seeds buried with precipitations since the sampling areas were protected from the predation. Then, considering the frequent irrigation regime used in the experimental field during the 3 mo of the seed shed period, differences in the intensity of some of these irrigations could lead to a burial of seeds in different proportions depending on the year. Seed predation is another factor that could cause differences between the two procedures, seed traps and vacuum sampling. Scopel et al. (1988) found that seed losses from the soil surface during the crop cycle varied between 3 and 15\% per day. Their results indicated that predators (most likely rodents) were the main causing agents. In our study area rodent populations were not observed and birds had no access to the seeds due to the close corn canopy. On the other hand, Westerman et al. (2008) observed the predation of weed seed in maize crop to be inversely density dependent. Since the proportion of seeds vacuumed remained constant in all studied distances, we consider the incorporation of seeds into the soil the main cause of the observed differences between both seed monitoring procedures, although we could not discard other causes.

In general, whatever the cause of seed loss during the 3 to 4 mo in which the seeds are shedding, the method with seed traps showed higher accuracy to collect seeds than the vacuum method. Because seed recovery was incomplete with vacuum sampling (23.7\% on average), measures from this procedure should be multiplied by a correction factor, as recommended by Penny et al. (2006), which in our circumstances was 4.35 on average for the $2 \mathrm{yr}$.

The GLM analyses were conducted separately for each year, since the quantity of seeds vacuumed in 2009 (849 seed $\mathrm{m}^{-2}$ ) was significantly higher than in 2010 (305 seeds $\mathrm{m}^{-2}$ ). In both years the collected seeds were not significantly different between patches or between directions (but more seeds were collected in NNE and ESE directions). The exponential model describing the relationship between the percentage of vacuumed seeds and the distance from the infestation source showed the same tendency than seeds collected in traps. In $2009,85 \%$ of the seeds were collected in the first $2 \mathrm{~m}$ and only $1.4 \%$ was beyond the first $5 \mathrm{~m}$ (Figure 2c). In 2010, $88 \%$ of the dispersed seeds were in the first $2 \mathrm{~m}$ and $0.5 \%$ of seeds were beyond the first $5 \mathrm{~m}$ (Figure $2 \mathrm{~d}$ ).
Seed Dispersal by the Combine Harvester. The lateral dispersal of johnsongrass seeds was practically nil outside the combine width. Only a slight displacement was observed when a patch could not be harvested in one single operation and two combine passes were required (data not shown). Postharvest vacuum sampling considered both, natural dispersal and combine dispersal (primary plus secondary dispersal). The GLM for the collected seeds did not show significant differences between years, patches, or forward and backward directions (NNE-SSW). The average number of collected seeds was 1,464 and 697 seeds $\mathrm{m}^{-2}$ in 2009 and 2010, respectively. The exponential model fitted to all the data showed a flatter curve (lower value of parameter $b$ ) than those described for natural dispersal (Figure 4). Around 86\% of the collected seeds were found in the first $2 \mathrm{~m}$ but seed dispersed were still $0.15 \%$ at $10 \mathrm{~m}$ from the patch edge.

Seed dispersal by the combine harvester (difference between seed collected postharvest from those collected preharvest) was significantly different in both years; hence, years were analyzed separately. In 2009, no significant differences were found between positions in relation with combine movement (forward or backward), between patches and between directions. The exponential model fitted to the data was relatively poor with $\mathrm{R}^{2}=0.342$ (Figure $5 \mathrm{a}$ ). The slope of the curve was much lower than those found in natural dispersal. Almost 23\% of the seeds were found under the parent plants, $90 \%$ were collected in the first $5 \mathrm{~m}$, and less than $1 \%$ was found beyond $20 \mathrm{~m}$ from the infestation source. Since the apparent backwards movement in 2009 could be due to seed contamination in the combine from the previous plot, in 2010 we decided to stop the combine 30 to $50 \mathrm{~m}$ before reaching the patch, keeping the threshing system working for a while in order to clean it from johnsongrass seeds. Probably due to this different procedure, the results obtained were much different (Figures 5b and 5c). Seed dispersal in the forward direction was more important than in the backward direction. Although similar percentages of seeds were collected in the first $5 \mathrm{~m}$ from the infestation source ( 90.4 and $93.5 \%$ in the forward and backward directions, respectively), a higher proportion of seeds were found at greater distances in the forward direction with $95 \%$ of the seeds collected at $26 \mathrm{~m}$ from the patch edge, while this percentage of seeds in the backward direction were collected at $12 \mathrm{~m}$ from the patch edge. This long-distance backward of dispersal may be due to the combined effects of seeds going through the thrashing process faster than the forward speed of the harvester, the own longitude of the combine harvester, as well as the fan situated under the sieves blowing the rest of straw and seeds outside the combine. The observed dispersal distances associated to the combine were similar to those reported for johnsongrass in Argentina (Ghersa et al. 1993) and for proso millet (Panicum miliaceum L.) in Canada (McCanny and Cavers 1988). Proso millet and johnsongrass seeds have similar sizes and they both shatter easily from the diffuse panicles when mature. Other weed species with larger seeds or with not freely detached seeds (like ryegrass or wild oats) were reported to have lower dispersal distances by the combine (Barroso et al. 2006; Blanco-Moreno et al. 2004; Rew et al. 1996). However, the timing of seed shedding is critical regarding seed dispersal by combines. If harvesting operations take place when most seeds have already shattered, dispersal will be much lower than when both processes take place simultaneously. 


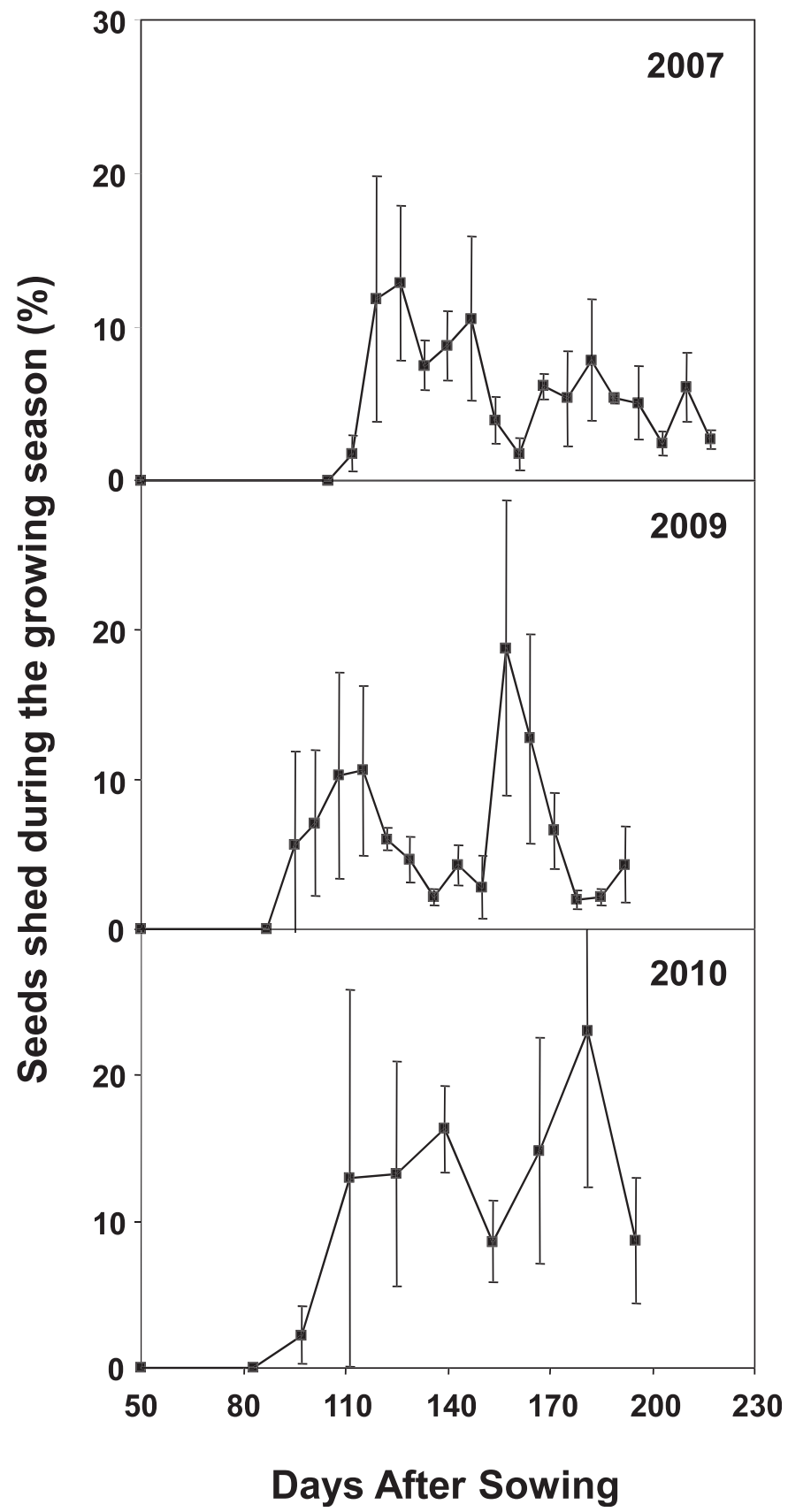

b)

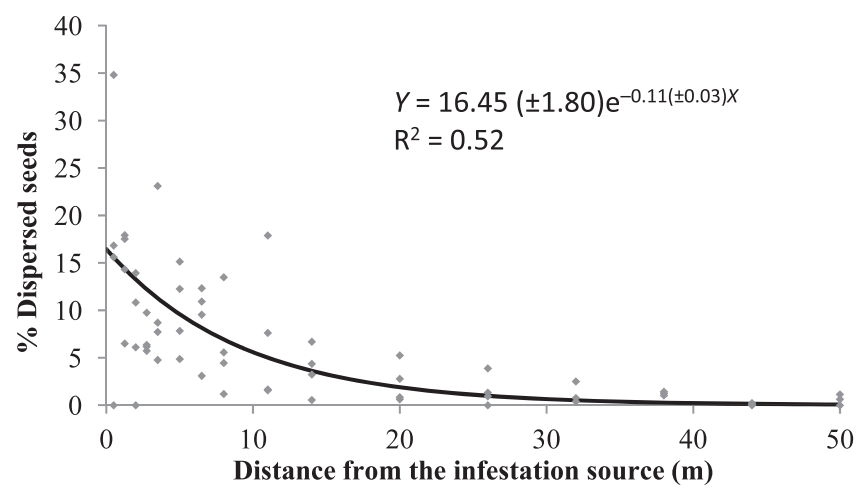

c)
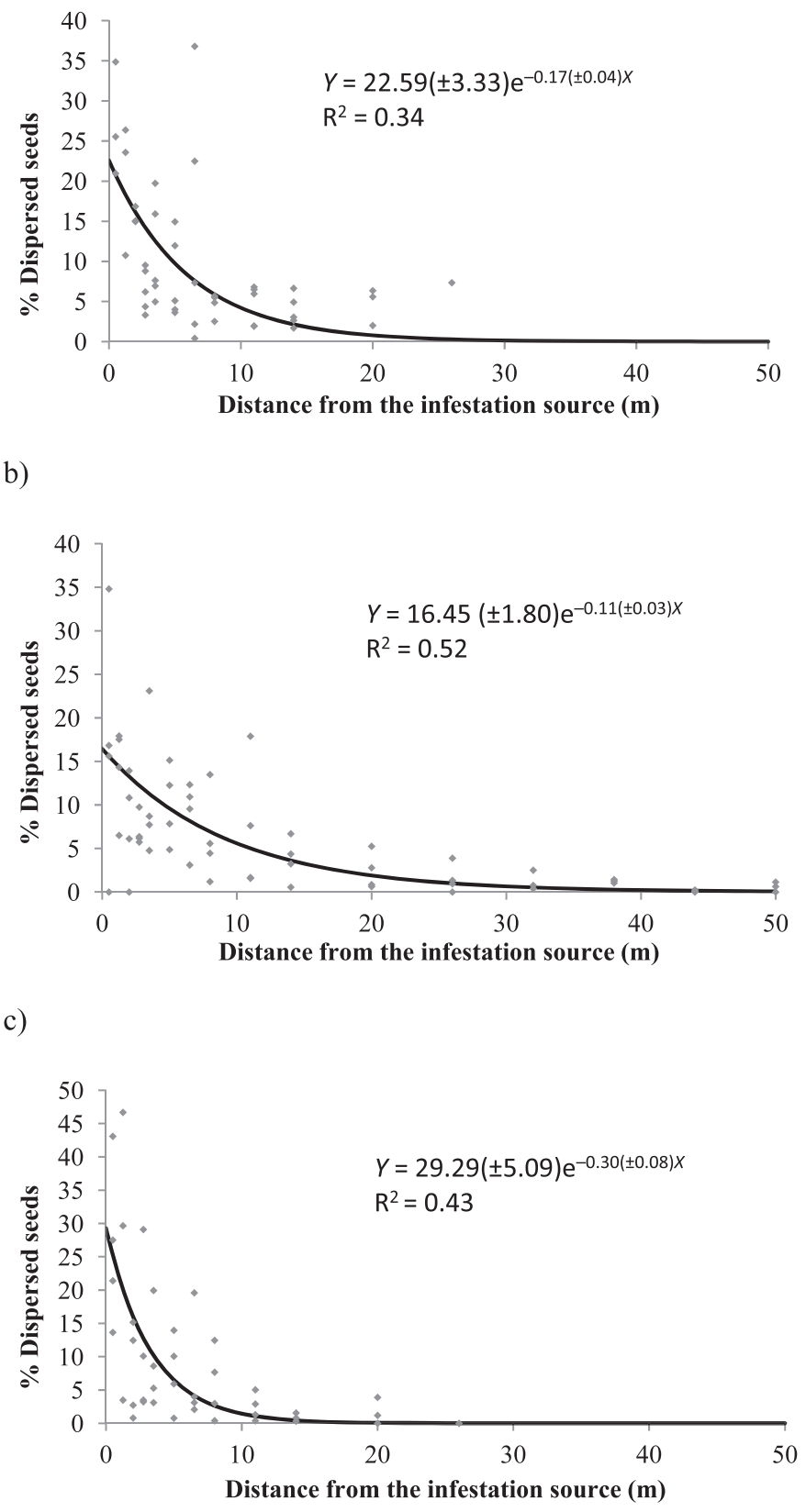

Figure 5. Combine seed dispersal in (a) 2009, forward and backward of the combine; (b) 2010, forward of the combine; and (c) 2010, backward of the combine.

Seed Shedding Pattern and Germination Tests. Seed shedding of johnsongrass started 3 mo after corn planting. This process continued during 3 or 4 additional months, with considerable fluctuations during its life cycle (Figure 6). The fluctuations in seed shedding were related neither with strong winds nor with irrigation/precipitation volume. The percentage of seeds still present in the panicles at harvest time (estimated by the difference between postharvest and preharvest collected seeds) was 38\% in 2009 and $67 \%$ in 2010. However, these percentages were probably higher because this calculation methodology does not include seeds that may become trapped into the combine. Ghersa et al. (1993) reported that at the harvesting time 40 to $60 \%$ of the

Figure 6. Temporal pattern of johnsongrass seed shedding in three patches with 14 seed traps each, during the three experimental years. Error bars represent the standard deviation of three replicates (three patches).

seeds had already shed and about $20 \%$ of the seeds remaining in the panicles were dispersed by the combine harvester. This lower value found in Argentina for seeds remaining in the panicles was probably due to different characteristic of the johnsongrass ecotypes (McWhorter 1971) and to different climatic conditions.

The number of seeds shed by each individual plant decreased exponentially as plant density increased, ranging from 2,350 seeds per plant when the weed density was 17 plants $\mathrm{m}^{-2}$ to 87 seeds per plant for a density of 63 plants $\mathrm{m}^{-2}$ (Figure 7).

A large proportion of the seeds collected were empty, shriveled, or damaged. In 2009 , only $14 \%$ of the seeds tested $(\mathrm{n}=2,500)$ were found in good apparent condition. In 


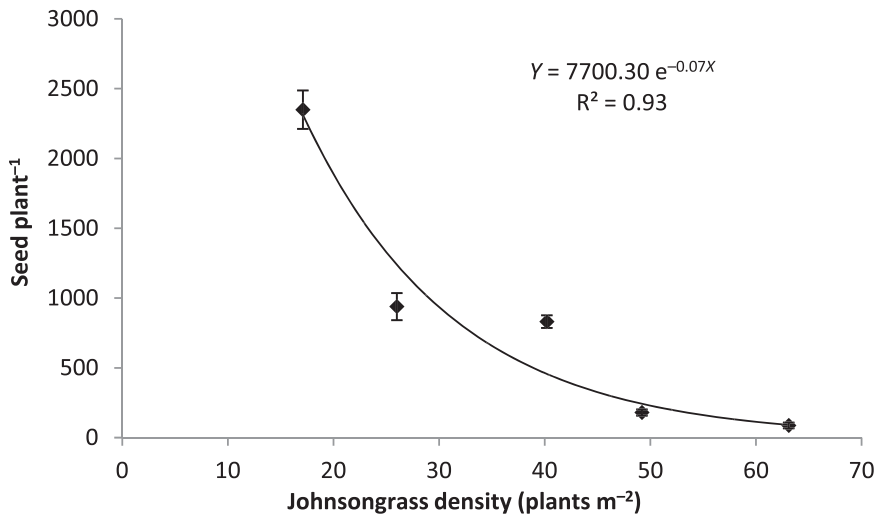

Figure 7. Relationship between johnsongrass density (plants $\mathrm{m}^{-2}$ ) and seed shedding per plant during 2009 and 2010 (patches P1, P2, and P3).

$2010,37 \%$ of the seeds collected in the seed traps $(\mathrm{n}=2,557)$ and $19 \%$ of the seeds collected with the vacuum device $(n=20,948)$ were found in good condition. In this last case, the proportion of full seeds was larger when seeds were vacuumed before harvest than after harvest $(25.9 \%$ vs. $15.4 \%)$. According to the germination tests conducted in 2010 , most recently released seeds were dormant or not viable. In contrast, germination was relatively high (up to $55 \%$ ) with seeds coming from the previous season (2009), particularly with those collected from July to mid September (Table 2). These results are in agreement with those reported by others authors (Harrington 1916, 1917; Taylorson and McWhorter 1969) reporting that fresh seeds of $S$. halepense have high dormancy but dry storage at room temperature for several months overcomes this dormancy.

Clonal perennial plants may have two contrasting strategies of population growth: phalanx and guerilla (Lovett Doust 1981). These two strategies differ fundamentally in their patterns of spread from a central point of establishment. Phalanx growth display compact, radially symmetric spread, whereas guerrilla growth exhibit directional dispersal, proliferating primarily along one or a few axes. In the specific case of johnsongrass, although patch spread generally follow a pattern typical of phalanx strategists, new infestation foci appear far away from the original patches (Andújar, personal communication). It is necessary to clarify the relative contribution of sexual and asexual propagules in this process. According to our results, most johnsongrass seeds were dispersed naturally a short distance $(<5 \mathrm{~m})$ from the parent plants. Prevailing wind direction was an important factor in determining dispersal direction. Combine harvesters acted as an important dispersal vector, moving the seeds up to $22 \mathrm{~m}$

Table 2. Germination of seed lots collected at different dates. Tests conducted in August to November 2010.

\begin{tabular}{lcc}
\hline Dates & Seeds $(\mathrm{n})$ & $\begin{array}{c}\text { Germination (standard } \\
\text { deviation, \%) }\end{array}$ \\
\hline July 30, 2009 & 700 & $41.60(9.31)$ \\
August 15, 2009 & 300 & $55.30(5.16)$ \\
September 10, 2009 & 300 & $55.00(13.2)$ \\
September 24, 2009 & 500 & $18.20(7.80)$ \\
October 16, 2009 & 300 & $28.70(7.44)$ \\
July 27, 2010 & 400 & $0.25(0.66)$ \\
August 10, 2010 & 700 & $0.15(0.45)$ \\
September 7, 2010 & 600 & $0.00(0.00)$ \\
September 21, 2010 & 300 & $0.33(0.81)$ \\
October 19, 2010 & 600 & $0.83(1.03)$ \\
\hline
\end{tabular}

forward and $10 \mathrm{~m}$ backward of the combine direction from the infestation source. The area gained by johnsongrass due to seed dispersal by the combine could have great impact on the rate of field infestations (Ballare et al. 1987). However, the actual role of these seeds is still not clear. Our results reveal that a large proportion of the seeds recently produced is dormant or not viable, although the rate of dormancy loss could be quick. In addition, plants coming from seeds are less competitive than plants coming from rhizomes (Mitskas et al. 2003) and they are more sensitive to applied herbicides. Consequently, because of the long distance seed dispersal favored by combine harvesting as well as the higher dormancy of seeds compared to rhizomes (Leguizamon 1986; McWhorter 1989), the major role of sexual reproduction in johnsongrass population dynamics may be to spread the risks promoting dispersal in time and space.

\section{Acknowledgments}

This research was funded by the Spanish National Research Council (JAE-DOC contract to Judit Barroso Pérez) and by the Spanish Interministerial Comission of Science and Technology (project AGL 2008-04670-C03).

\section{Literature Cited}

Andújar, D., D. Ruiz, A. Ribeiro, C. Fernández-Quintanilla, and J. Dorado 2011. Spatial distribution patterns of johnsongrass (Sorghum halepense) in corn fields in Spain. Weed Sci. 59:82-89.

Ballare, C. L., A. L. Scopel, C. M. Ghersa, and R. A. Sanchez. 1987. The demography of Datura ferox (L.) in soybean crops. Weed Res. 27:91-102.

Barroso, J., C. Fernández-Quintanilla, D. Ruiz, P. Hernaiz, and L. J. Rew. 2004. Spatial stability of Avena sterilis ssp. ludoviciana populations under annual applications of low rates of imazamethabenz. Weed Res. 44:178-186.

Barroso, J., L. Navarrete, M. J. Sánchez del Arco, C. Fernández-Quintanilla, P.J.W. Lutman, N. H. Perry, and R. I. Hull. 2006. Dispersal of Avena fatua and Avena sterilis patches by natural dissemination, soil tillage and combine harvesters. Weed Res. 46:118-128.

Bendixen, L. E. 1986. Corn (Zea mays) yield in relationship to johnsongrass (Sorghum halepense) population. Weed Sci. 34:449-451.

Blanco-Moreno, J. M., L. Chamorro, R. M. Masalles, J. Recasens, and F. X. Sans. 2004. Spatial distribution of Lolium rigidum seedlings following seed dispersal by combine harvesters. Weed Res. 44:375-387.

Evans, D. M., J. J. Mcleod, L. Pascoe, and J. Memmott. 2009. The efficiency of a vacuum device for estimating soil-surface seed abundance on lowland farms. Weed Res. 49:337-340.

Ghersa, C. M., M. A. Martinez-Ghersa, E. H. Satorre, M. L. Van Esso, and G. Chichotky. 1993. Seed dispersal, distribution and recruitment of seedlings of Sorghum halepense (L.) Pers. Weed Res. 33:79-88.

Ghosheh, H. Z., D. L. Holshouser, and J. M. Chadler. 1996. Influence of density on johnsongrass (Sorghum halepense) interference in field corn (Zea mays) Weed Sci. 44:879-883.

Harrington, G. T. 1916. Germination and viability tests of Johnson grass seed Proc. Assoc. Official Seed Anal. 9:24-28.

Harrington, G. T. 1917. Further studies of the germination of Johnson grass seeds. Proc. Assoc. Official Seed Anal. 10:71-76.

Heijting, S., W. Van der Werf, and M. J. Kropff. 2009. Seed dispersal by forage harvester and rigid-tine cultivator in maize. Weed Res. 49:153-163.

Holm, L.R.G., D. L. Plucknett, J. V. Pancho, and J. P. Herberger. 1977. The World's Worst Weeds: Distribution and Biology. Honolulu, HI: The University Press of Hawaii. Pp. 54-61.

Horowitz, M. 1973. Spatial growth of Sorghum halepense. Weed Res. 13:200-208.

Howard, C. L., A. M. Mortimer, P. Gould, P. D. Putwain, R. Cousens, and G. W. Cussans. 1991. The dispersal of weeds: seed movement in arable agriculture. Pages 821-828 in Proc. of the Brighton Crop Protection Conference-Weeds. Lavenham, UK: The Lavenham Press.

Leguizamon, E. S. 1986. Seed survival and patterns of seedling emergence in Sorghum halepense (L.) Pers. Weed Res. 26:397-403. 
Lolas, P. C. and H. D. Coble. 1982. Noncompetitive effects of johnsongrass (Sorghum halepense) on soybeans (Glycine max). Weed Sci. 30:589-593.

Lovett Doust, L. 1981. Population dynamics and local specialization in a clonal perennial (Ranunculus repens). I. The dynamics of ramets in contrasting habitats. J. Ecol. 69:743-755.

McCanny, S. J. and P. B. Cavers. 1988. Spread of proso millet (Panicum miliaceum L.) in Ontario, Canada. II. Dispersal by combines. Weed Res. 28:67-72.

McWhorter, C. G. 1971. Growth and development of johnsongrass ecotypes. Weed Sci. 19:141-147.

McWhorter, C. G. 1989. History, biology, and control of johnsongrass. Rev. Weed Sci. 4:85-121.

Mitskas, M. B., I. G. Eleftherohorinos, and C. A. Damalas. 2003. Interference between corn and johnsongrass (Sorghum halepense) from seed or rhizomes. Weed Sci. 51:540-545.

Penny, E. J., R. M. Kaminski, and K. J. Reinecke. 2006. A new device to estimate abundance of moist-soil plant seeds. Wildlife Soc. Bull. 34:186-190.

Rew, L. J. and G. W. Cussans. 1997. Horizontal movement of seeds following tine and plough cultivation: implications for spatial dynamics of weed infestations. Weed Res. 37:247-256.
Rew, L. J., R. J. Froud-Williams, and N. D. Boatman. 1996. Dispersal of Bromus sterilis and Anthriscus sylvestris seed within arable field margin. Agric. Ecosyst. Environ. 59:107-114

Scopel, A. L., C. L. Ballare, and C. M. Ghersa. 1988. Role of seed reproduction in the population ecology of Sorghum halepense in maize crops. J. Appl. Ecol. 25:951-962.

Shirtliffe, S. J. and M. H. Entz. 2005. Chaff collection reduces seed dispersal of wild oat (Avena fatua) by a combine harvester. Weed Sci. 53:465-470.

[SPSS] Statistical Product and Service Solutions. 2010. IBM SPSS ${ }^{\circledR}$ Amos $^{\text {TM }} 19$ User's Guide. Chicago, IL: SPSS Inc.

Taylorson, R. B. and C. G. McWhorter. 1969. Seed dormancy and germination in ecotypes of johnsongrass. Weed Sci. 17:359-361.

Van Wychen, L. R., E. C. Luschei, A. J. Bussan, and B. D. Maxwell. 2002. Accuracy and cost effectiveness of GPS-assisted wild oat mapping in spring cereal crops. Weed Sci. 50:120-129.

Westerman, P. R., J. K. Borza, J. Andjelkovic, M. Liebman, and B. Danielson. 2008. Density-dependent predation of weed seeds in maize field. J. Appl. Ecol. 45:1612-1620.

Received June 13, 2011, and approved August 16, 2011. 